\title{
The value of systemic inflammatory markers in identifying malignancy in mucinous pancreatic cystic neoplasms
}

\author{
Wentao Zhou ${ }^{1, *}$, Yefei Rong ${ }^{1, *}$, Tiantao Kuang ${ }^{1, *}$, Yadong $\mathrm{Xu}^{2}$, Xiaojing Shen ${ }^{3}$, Yuan \\ $\mathrm{Ji}^{3}$, Wenhui Lou ${ }^{2}$ and Dansong Wang ${ }^{1}$ \\ ${ }^{1}$ Department of General Surgery, Zhong Shan Hospital, Fudan University, Shanghai, China \\ ${ }^{2}$ Department of Pancreatic Surgery, Zhong Shan Hospital, Fudan University, Shanghai, China \\ ${ }^{3}$ Department of Pathology, Zhong Shan Hospital, Fudan University, Shanghai, China \\ *These authors have contributed equally to this work
}

Correspondence to: Dansong Wang, email: wang.dansong@outlook.com

Keywords: systemic inflammatory markers; pancreatic cystic neoplasm; invasive carcinoma; platelet-to-lymphocyte ratio; lymphocyte-to-monocyte ratio

Received: August 23, $2017 \quad$ Accepted: December 04, $2017 \quad$ Published: December 14, 2017

Copyright: Zhou et al. This is an open-access article distributed under the terms of the Creative Commons Attribution License 3.0 (CC BY 3.0), which permits unrestricted use, distribution, and reproduction in any medium, provided the original author and source are credited.

\section{ABSTRACT}

The treatment decision-making of mucinous pancreatic cystic neoplasm (PCN) has become a common clinical problem since the diagnostic accuracy of current tests in identifying malignancies in pancreatic cysts is limited. In this study, we aimed to validate the predictive value of systemic inflammatory factors in detecting malignant PCNs. Two hundred and forty-five patients with pathologically confirmed mucinous PCNs in a single Chinese institution were retrospectively analyzed. Receiver operating characteristic (ROC) curves were calculated to determine the optimal cut-off values and measure the diagnostic value. The results showed that neutrophil count $(P=$ 0.009), lymphocyte count $(P=0.002)$, neutrophil-to-lymphocyte ratio (NLR, $P<$ $0.001)$, platelet-to-lymphocyte ratio ( PLR, $P<0.001)$ and lymphocyte-to-monocyte ratio (LMR, $P<0.001$ ) were distributed differently among the various differentiation groups of PCN. The univariate analyses indicated that a neutrophil count $\geq 2.8 \times$ $10^{\circ} / \mathrm{L}(P=0.024)$, lymphocyte count $\leq 1.9 \times 10^{\circ} / \mathrm{L}(P<0.001)$, PLR $\geq 125(P<$ $0.001), N L R \geq 1.96(P<0.001)$, and LMR $\leq 4.29(P<0.001)$ were significantly associated with invasive carcinomas in PCN patients. In addition, the multivariate analyses demonstrated that $P L R \geq 125$ and $L M R \leq 4.29$ were independent predictors of invasive malignancies. The ROC curves exhibited the malignant detection utility of the independent factor-based predictive model with an area under the curve (AUC) of $0.858(P<0.001)$. In conclusion, systemic inflammatory markers provide a supportive and easily accessible tool for the preoperative diagnoses of malignant PCNs.

\section{INTRODUCTION}

Mucin-producing pancreatic cystic neoplasms (PCNs) are precancerous lesions and comprise intraductal papillary mucinous neoplasm (IPMN) and mucinous cystic neoplasm (MCN). With an increasingly incidental detection using advanced cross-sectional imaging, the management of mucinous PCNs has gradually become a common clinical conundrum of balancing the risk of malignant transformation with the morbidity and mortality of surgical resection [1]. The Sendai consensus guidelines and subsequent updated Fukuoka consensus guidelines have been widely adopted as an algorithm to direct the treatment strategies for mucinous PCN patients [2,3]. The high-risk parameters for malignancy in the guidelines were verified by several retrospective studies, but the outcomes 
have been controversial $[4,5]$. Some articles reported that many mucinous PCNs did not meet these criteria and were still proven to harbor high-grade dysplasia or even invasive cancers, and the validity of the guidelines were doubtful $[6,7]$. Thus, novel and accurate diagnostic indexes are required to discriminate benign lesions from invasive malignancies.

The relationship between inflammation and a tumor has been researched for more than 100 years, when it was first proposed by Virchow [8]. Accumulating evidence indicates that systemic inflammation plays a pivotal role in the initiation and progression of malignant tumors via the release of cytokines and other mediators [9-12]. Several circulating blood-cell-based markers, such as the neutrophil-to-lymphocyte ratio (NLR), platelet-tolymphocyte ratio (PLR), and lymphocyte-to-monocyte ratio (LMR), are reflections of host systemic responses to malignancies and have been validated as independent prognostic factors in various solid tumors [13-16]. Recently, the malignancy-predicting role of preoperative NLR and PLR in PCN patients has gained much attention $[1,17]$.

This study was designed to assess the utility of inflammatory markers in identifying invasive carcinomas in a cohort of all mucinous PCN patients, which is difficult to distinguish using radiological images due to the overlapping morphological features between IPMN and $\mathrm{MCN}$.

\section{RESULTS}

A total of 245 patients with mucinous pancreatic cystic neoplasms were enrolled into this retrospective study. The present cohort was comprised of 149 females and 96 males with a median age of 58 years (IQR 4865 years). Nearly half $(\mathrm{n}=116,47.3 \%)$ of the patients presented with symptoms, and most of these were epigastric discomfort. The majority $(n=120,49.0 \%)$ of the patients underwent distal pancreatectomy, and 14 of them had the spleen preserved. Other surgical procedures included pancreatoduodenectomy $(\mathrm{n}=89,36.3 \%)$, middle segmentectomy $(\mathrm{n}=12,4.9 \%)$, enucleation $(\mathrm{n}=$ $16,6.5 \%)$ and total pancreatectomy $(\mathrm{n}=8,3.3 \%)$. There were $162(66.1 \%)$ IPMN cases and 83 (33.9\%) MCN cases confirmed by pathology. The IPMNs were further classified as subtypes of the main duct $(\mathrm{n}=55,34.0 \%)$, branch duct $(\mathrm{n}=58,35.8 \%)$ and mixed type $(\mathrm{n}=35$, $21.6 \%)$. Additional clinicopathological characteristics are detailed in Table 1.

\section{The distribution of inflammatory markers in mucinous PCNs stratified by differentiation}

Based on the histological differentiation of surgical resections, mucinous $\mathrm{PCNs}$ were divided into low-grade dysplasia $(n=94,38.4 \%)$, moderate-grade dysplasia $(n$
$=54,22 \%)$, high-grade dysplasia $(\mathrm{n}=48,19.6 \%)$ and invasive carcinoma $(n=49,20 \%)$. The first two were defined as benign lesions. The distribution of inflammatory markers in the various differentiation groups are shown in Figure 1. Except for platelet count, white blood cell count and monocyte count, all the other markers were distributed differently in these groups. Further comparisons of every two groups indicated that neutrophil count $(P=0.006)$, NLR $(P<0.001)$ and PLR $(P<0.001)$ were significantly elevated, whereas lymphocyte count $(P=0.006)$ and LMR $(P<0.001)$ were declined in invasive carcinomas compared with the low-/moderate-grade dysplasia group, respectively. Compared with the high-grade dysplasia group, the NLR $(P=0.006)$ and PLR $(P=0.001)$ were increased, and lymphocyte count $(P=0.003)$ was reduced in the invasive carcinoma group. However, none of the inflammatory factors displayed different distributions between the benign and high-grade dysplasia group.

\section{Univariate and multivariate analyses of predictive factors for invasive carcinoma}

The optimal cut-off values of these inflammatory markers were calculated via the ROC curves. Univariate analyses indicated that neutrophil count $\geq 2.8 \times 10^{9} / \mathrm{L}(P$ $=0.024)$, lymphocyte count $\leq 1.9 \times 10^{9} / \mathrm{L}(P<0.001)$, PLR $\geq 125(P<0.001)$, NLR $\geq 1.96(P<0.001)$, and LMR $\leq 4.29(P<0.001)$ were significantly associated with mucinous PCN-derived invasive carcinoma (Table 2). In addition, patients who were over 61 years old $(P$ $=0.014)$ and presented with symptoms $(P=0.013)$ were more prone to developing cancer. Radiological parameters of tumor size $\geq 49 \mathrm{~mm}(P=0.003)$ and main pancreatic duct (MPD) diameter $\geq 10 \mathrm{~mm}(P<0.001)$ also showed their predictive utilities in detecting invasive malignancy. In addition, of the 49 invasive carcinoma cases, 42 were derived from IPMN, and 7 were from MCN. The IPMN had a much higher chance than the MCN to turn into invasive cancer ( $25.9 \%$ vs. $8.4 \%$, respectively, $P=0.001$ ). Further multivariate analyses demonstrated that tumor size $\geq 49 \mathrm{~mm}(P=0.002)$, MPD diameter $\geq 10 \mathrm{~mm}(P$ $=0.005)$, CA19-9 $\geq 42.7 \mathrm{U} / \mathrm{mL}(P=0.005)$, CEA $\geq 1.9$ $\mathrm{ng} / \mathrm{mL}(P=0.002), \mathrm{PLR} \geq 125(P=0.021)$, and $\mathrm{LMR} \leq$ $4.29(P=0.001)$ were independent predictors of invasive carcinoma (Table 3). The AUC of the ROC curves of these independent factors including tumor size $\geq 49 \mathrm{~mm}$, MPD diameter $\geq 10 \mathrm{~mm}, \mathrm{CA} 19-9 \geq 42.7 \mathrm{U} / \mathrm{mL}, \mathrm{CEA} \geq 1.9 \mathrm{ng} /$ $\mathrm{mL}, \mathrm{PLR} \geq 125$, and LMR $\leq 4.29$ curves were 0.617 , $0.595,0.664,0.722,0.691$ and 0.667 , respectively (Figure 2B).

\section{Construction and validation of the predictive model}

All the above independent predictors were enrolled to establish the predictive model for invasive malignancy. 
Table 1: Clinicopathological characteristics of resected patients with mucinous pancreatic cystic neoplasms

\begin{tabular}{|c|c|}
\hline Characteristics & $n=245$ \\
\hline Age, years (median, IQR) & $58(48-65)$ \\
\hline \multicolumn{2}{|l|}{$\operatorname{Sex}(n, \%)$} \\
\hline Female & $149(60.8 \%)$ \\
\hline Male & $96(39.2 \%)$ \\
\hline Symptom, present (n, \%) & $116(47.3 \%)$ \\
\hline Tumor size, mm (median, IQR) & $35(20-54)$ \\
\hline Main pancreatic duct diameter $\geq 10 \mathrm{~mm}(\mathrm{n}, \%)$ & $28(11.4 \%)$ \\
\hline \multicolumn{2}{|l|}{ Surgical style (n, \%) } \\
\hline Pancreatoduodenectomy & $89(36.3 \%)$ \\
\hline Distal pancreatectomy/spleen preserved & $120(49.0 \%) / 14(11.7 \%)$ \\
\hline Total pancreatectomy & $8(3.3 \%)$ \\
\hline Middle segmentectomy & $12(4.9 \%)$ \\
\hline Enucleation & $16(6.5 \%)$ \\
\hline Harvested lymph nodes, n (median, IQR) & $4(0-8)$ \\
\hline \multicolumn{2}{|l|}{ Pathology (n, \%) } \\
\hline Intraductal papillary mucinous neoplasm & $162(66.1 \%)$ \\
\hline Main duct & $55(34.0 \%)$ \\
\hline Mixed type & $35(21.6 \%)$ \\
\hline Branch duct & $58(35.8 \%)$ \\
\hline Unknown & $14(8.6 \%)$ \\
\hline Mucinous cystic neoplasm & $83(33.9 \%)$ \\
\hline Albumin, g/L (median, IQR) & $40(38-42)$ \\
\hline CA19-9, U/mL (median, IQR) & $12.6(7.0-25.1)$ \\
\hline Unknown (n, \%) & $10(4.1 \%)$ \\
\hline CEA, ng/mL (median, IQR) & $2.0(1.3-3.2)$ \\
\hline Unknown (n, \%) & $11(4.5 \%)$ \\
\hline Platelet count, $\times 10^{9} / \mathrm{L}$ (median, IQR) & $199(164-236)$ \\
\hline White blood cell count, $\times 10^{9} / \mathrm{L}$ (median, IQR) & $5.3(4.5-6.1)$ \\
\hline Neutrophil count, × 109/L (median, IQR) & $2.9(2.2-3.6)$ \\
\hline Lymphocyte count, × 109/L (median, IQR) & $1.8(1.5-2.1)$ \\
\hline Monocyte count, $\times 10^{9} / \mathrm{L}$ (median, IQR) & $0.36(0.29-0.47)$ \\
\hline Platelet-to-lymphocyte ratio (median, IQR) & $110.0(92.6-141.7)$ \\
\hline Neutrophil-to-lymphocyte ratio (median, IQR) & $1.61(1.21-2.13)$ \\
\hline Lymphocyte-to-monocyte ratio (median, IQR) & $4.88(3.70-6.35)$ \\
\hline
\end{tabular}

CA19-9, carbohydrate antigen 19-9; CEA, carcinoembryonic antigen; IQR, interquartile range. 
The value of each variable was assigned based on the odds ratio (Table 3), and a point of 0 was allotted if a predictive factor was not possessed. The predictive index score $=3$ (if tumor size $\geq 49 \mathrm{~mm}$ ) +4 (if MPD diameter $\geq 10 \mathrm{~mm}$ ) +3 (if CA19-9 $\geq 42.7 \mathrm{U} / \mathrm{mL})+3$ (if CEA $\geq 1.9 \mathrm{ng} / \mathrm{mL}$ ) $+2($ if PLR $\geq 125)+3($ if $L M R \leq 4.29)$. The median of the predictive index score was 5 with a range between 0 and 18 .

The predictive value of the model was assessed by using the ROC curve. A point of 5 was calculated as the optimal predictive index score with a sensitivity of $87.76 \%$ and a specificity of $68.11 \%$. The AUC of this model was 0.858 (Figure 2A). The ROC curve comparison analyses showed that the predictive model had a much a better detecting ability than any individual predictors (Table 4).

\section{DISCUSSION}

Given the malignant potential of mucinous PCNs, the precise selection of patients who will benefit from surgical resections and those who will benefit from close follow-ups is crucial but difficult. Mainly, and based on imaging characteristics, high-risk signs for malignancies in pancreatic cysts including enhanced solid component, MPD size $\geq 10 \mathrm{~mm}$, and obstructive jaundice were presented as surgical indications by the current international consensus guidelines. However, the sensitivity and specificity of these criteria in predicting high-grade dysplasia and invasive carcinoma varied largely in many retrospective cohorts, and the accuracy was not satisfied by most authors [18-21]. Thus, the investigations of appropriate diagnostic biomarkers have been conducted.

Recently, there has been a great interest in the inflammatory markers NLR and PLR in detecting malignant transformed mucinous PCNs. In our study, we analyzed the distributions of NLR and PLR in mucinous PCNs with different degrees of dysplasia. The results showed that both NLR and PLR were significantly elevated in patients with invasive carcinomas. The univariate analyses suggested that NLR $\geq 1.96$ and PLR $\geq 125$ were predictive markers of mucinous PCN-derived invasive carcinoma. In the multivariate analyses, only PLR was an independent predictor of invasive cancer, which was in accordance with the results from a report of Goh et al. [22]. The major differences were that some confounding factors regarding the selection of patients were excluded, and a doubled sample size was involved in our research. However, Gemenetzis et al. [17] and Arima et al. [23] reported that a high NLR rather than PLR was an independent predictor for invasive cancers in pancreatic cysts, respectively. This distinction could be explained in that only IPMN patients were enrolled in their studies. In clinical practice, the differential diagnosis between IPMN and $\mathrm{MCN}$ by preoperative imaging tests was limited even by endoscopic ultrasound and cyst fluid analysis [24].

An elevated PLR could be a consequence of an increased number of platelets, a decreased lymphocyte
A

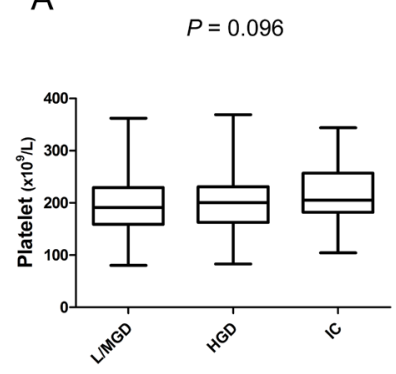

E

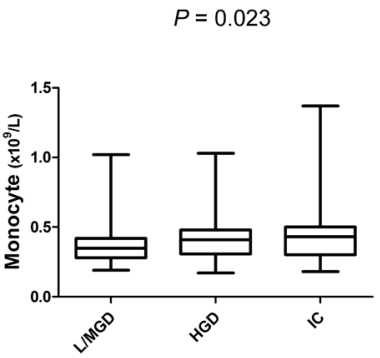

B

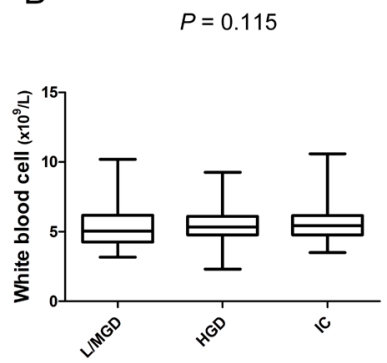

F

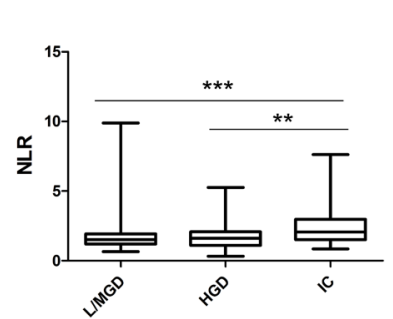

C

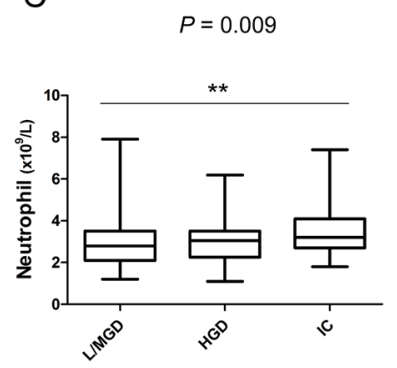

G

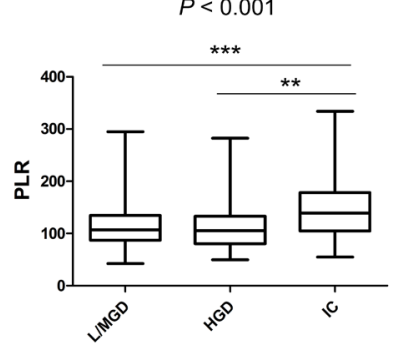

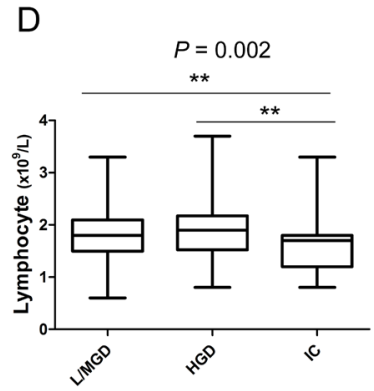

$\mathrm{H}$

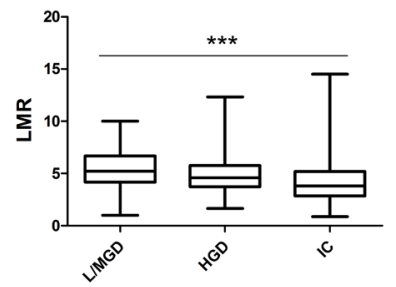

Figure 1: Box-plot diagrams were drawn according to the distribution of inflammatory markers in mucinous pancreatic cystic neoplasms stratified by pathology. (A) platelet count; (B) white blood cell count; (C) neutrophil count; (D) lymphocyte count; (E) monocyte count; (F) neutrophil-to-lymphocyte ratio; (G) platelet-to-lymphocyte ratio; (H) lymphocyte-to-monocyte ratio. L/MGD, low-/moderate-grade dysplasia; HGD, high-grade dysplasia; and IC, invasive carcinomas. ${ }^{* *}, P<0.01{ }^{* * *}, P<0.001$. 
Table 2: Univariate analyses of predictors of invasive carcinomas derived from mucinous pancreatic cystic neoplasms

\begin{tabular}{|c|c|c|c|c|}
\hline Characteristic, n (\%) & $\begin{array}{l}\text { Low-/moderate-grade } \\
\text { dysplasia }(n=148)\end{array}$ & $\begin{array}{l}\text { High-grade dysplasia } \\
\qquad(\mathrm{n}=48)\end{array}$ & $\begin{array}{l}\text { Invasive carcinoma } \\
\qquad(\mathrm{n}=49)\end{array}$ & $\begin{array}{c}\text { Non-invasive vs } \\
\text { invasive, } P\end{array}$ \\
\hline Age $\geq 61$ years & $44(29.7 \%)$ & $34(70.8 \%)$ & $29(59.2 \%)$ & 0.014 \\
\hline Male & $43(29.1 \%)$ & $29(60.4 \%)$ & $24(49.0 \%)$ & 0.116 \\
\hline Symptom, present & $62(41.9 \%)$ & $23(47.9 \%)$ & $31(63.3 \%)$ & 0.013 \\
\hline Tumor size $\geq 49 \mathrm{~mm}$ & $45(30.4 \%)$ & $11(22.9 \%)$ & $25(51.0 \%)$ & 0.003 \\
\hline MPD diameter $\geq 10 \mathrm{~mm}$ & $6(4.1 \%)$ & $9(18.8 \%)$ & $13(26.5 \%)$ & $<0.001$ \\
\hline Pathology & & & & 0.001 \\
\hline IPMN & $73(49.3 \%)$ & $47(97.9 \%)$ & $42(85.7 \%)$ & \\
\hline $\mathrm{MCN}$ & $75(50.7 \%)$ & $1(2.1 \%)$ & $7(14.3 \%)$ & \\
\hline IPMN classification & & & & 0.014 \\
\hline Main duct & $20(27.4 \%)$ & $17(36.2 \%)$ & $18(42.9 \%)$ & \\
\hline Mixed type & $12(16.4 \%)$ & $11(23.4 \%)$ & $12(28.6 \%)$ & \\
\hline Branch duct & $36(49.3 \%)$ & $15(31.9 \%)$ & $7(16.7 \%)$ & \\
\hline Unknown & $5(6.8 \%)$ & $4(8.5 \%)$ & $5(11.9 \%)$ & \\
\hline Albumin $\leq 39 \mathrm{~g} / \mathrm{L}$ & $50(33.8 \%)$ & $24(50.0 \%)$ & $25(51.0 \%)$ & 0.091 \\
\hline CA19-9 $\geq 42.7 \mathrm{U} / \mathrm{mL}^{*}$ & $12(8.6 \%)$ & $6(12.8 \%)$ & $19(38.8 \%)$ & $<0.001$ \\
\hline $\mathrm{CEA} \geq 1.9 \mathrm{ng} / \mathrm{mL}^{\#}$ & $55(39.9 \%)$ & $29(61.7 \%)$ & $40(81.6 \%)$ & $<0.001$ \\
\hline Neutrophil count $\geq 2.8 \times 10^{9} / \mathrm{L}$ & $77(52.0 \%)$ & $28(58.3 \%)$ & $35(71.4 \%)$ & 0.024 \\
\hline $\begin{array}{l}\text { Lymphocyte count } \leq 1.9 \\
\times 10^{9} / \mathrm{L}\end{array}$ & $59(39.9 \%)$ & $22(45.8 \%)$ & $7(14.3 \%)$ & $<0.001$ \\
\hline PLR $\geq 125$ & $45(30.4 \%)$ & $15(31.3 \%)$ & $32(65.3 \%)$ & $<0.001$ \\
\hline $\mathrm{NLR} \geq 1.96$ & $34(23.0 \%)$ & $12(25.0 \%)$ & $28(57.1 \%)$ & $<0.001$ \\
\hline $\mathrm{LMR} \leq 4.29$ & $41(27.7 \%)$ & $16(33.3 \%)$ & $32(65.3 \%)$ & $<0.001$ \\
\hline
\end{tabular}

MPD, main pancreatic duct; IPMN, intraductal papillary mucinous neoplasm; MCN, mucinous cystic neoplasm; CA19-9, carbohydrate antigen 19-9; CEA, carcinoembryonic antigen; WBC, white blood cell; PLR, platelet-to-lymphocyte ratio; NLR, neutrophil-to-lymphocyte ratio; LMR, lymphocyte-to-monocyte ratio; ${ }^{*}, \mathrm{n}=235 ;{ }^{*}, \mathrm{n}=234$.

Table 3: Multivariate analyses of predictors for invasive carcinoma and predictive index score according to the odds ratio $(n=234)$

\begin{tabular}{lcccc}
\hline Characteristic & Odds ratio & $\mathbf{9 5 \%}$ CI & $\boldsymbol{P}$ & Predictive index score \\
\hline Tumor size $\geq 49 \mathrm{~mm}$ & 3.852 & $1.670-8.882$ & 0.002 & 3 \\
MPD diameter $\geq 10 \mathrm{~mm}$ & 4.565 & $1.578-13.205$ & 0.005 & 4 \\
CA19-9 $\geq 42.7 \mathrm{U} / \mathrm{mL}$ & 3.704 & $1.482-9.255$ & 0.005 & 3 \\
CEA $\geq 1.9 \mathrm{ng} / \mathrm{mL}$ & 3.967 & $1.665-9.452$ & 0.002 & 3 \\
PLR $\geq 125$ & 2.538 & $1.149-5.604$ & 0.021 & 2 \\
LMR $\leq 4.29$ & 3.857 & $1.695-8.775$ & 0.001 & 3 \\
\hline
\end{tabular}

MPD, main pancreatic duct; CA19-9, carbohydrate antigen 19-9; CEA, carcinoembryonic antigen; PLR, platelet-tolymphocyte ratio; LMR, lymphocyte-to-monocyte ratio; CI, confidence interval. 
amount or both. Possible explanations regarding the relationship between PLR and pancreatic carcinogenesis are described in several other studies. The release of cytokines such as IL-1, IL-3 and IL-6 in the proinflammatory phase can stimulate the activation of megakaryocytes, which results in thrombocytosis [25]. However, growth factors, including platelet-derived growth factor, platelet factor 4 and TGF- $\beta$ generated by platelets, can promote the proliferation and invasion of tumor cells [26, 27]. Apart from inflammation, the suppression of the lymphocyte-mediated immune response by inhibitory mediators such as IL-10 and TGF- $\beta$ also plays a crucial role in the progression of pancreatic carcinomas $[28,29]$. Thus, a high circulating cell-based PLR may be a magnified reflection of both the inflammatory and immune response in the regional tumor microenvironment. Additionally, another inflammatory index of LMR demonstrated the independent predictive role of invasive carcinoma in our cohort. To our understanding, this is the first research investigating LMR in pancreatic cystic neoplasms. Based on our findings, we provide a novel serum marker for the individual patient's risk assessment at the time of PCN diagnosis. Previous studies have reported that local tumorassociated macrophages mainly recruited from circulating monocytes could exert immunosuppressive influences on facilitating tumor growth and angiogenesis [30]. Thus, LMR undertakes a similar indicative role of the complex tumor microenvironment as that of PLR. The independent predictive value of both PLR and LMR in identifying

A

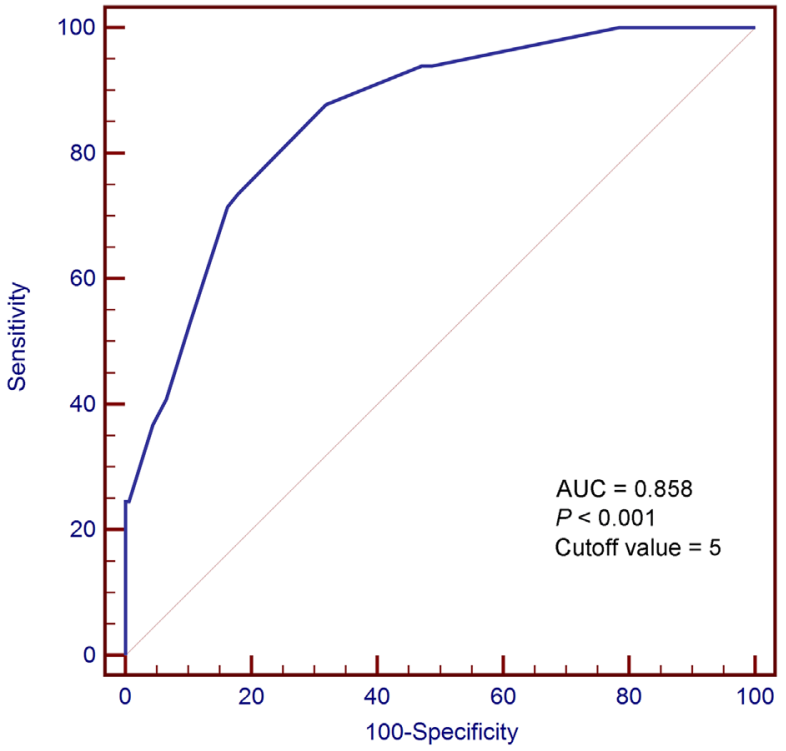

invasive carcinomas provides a certain support for making therapeutic decisions regarding mucinous PCNs.

We further evaluated the predictive abilities of these inflammatory biomarkers by using ROC curves, and the AUC of PLR and LMR were 0.691 and 0.667, respectively. The results indicated that both PLR and LMR could not serve as ideal diagnostic markers of mucinous PCN patients harboring invasive cancers. To establish an effective predictive model for mucinous PCN-derived malignancies, four other independent factors including tumor size $\geq 49 \mathrm{~mm}$, MPD diameter $\geq 10 \mathrm{~mm}$, CA19-9 $\geq 42.7 \mathrm{U} / \mathrm{mL}$ and $\mathrm{CEA} \geq 1.9 \mathrm{ng} / \mathrm{mL}$ were incorporated. The AUC of our predictive model was 0.858 , which showed a significantly superior performance in detecting malignancy than any individual components. The optimal predictive value of this model was 5 with a sensitivity of $87.76 \%$ but a relatively low specificity of $68.11 \%$, which would bring about unnecessary resections of benign lesions. However, in our study, only 24 (27.6\%) of the cases without invasive cancers but that scored $\geq$ 5 were branch-duct IPMNs (BD-IPMNs); all other types of mucinous PCNs were recommended for surgical resections due to the high risk of malignant transformation by the guidelines. In addition, 10 of the 24 BD-IPMNs were pathologically confirmed with high-grade dysplasia, and surgical interventions were imperative for these cases. In general, since 4 serum markers and 2 cross-sectional imaging-based features are collected from routinely preoperative assessments, our predictive model is easily accessible and helpful for clinicians to identify malignancy in patients with mucinous PCNs.

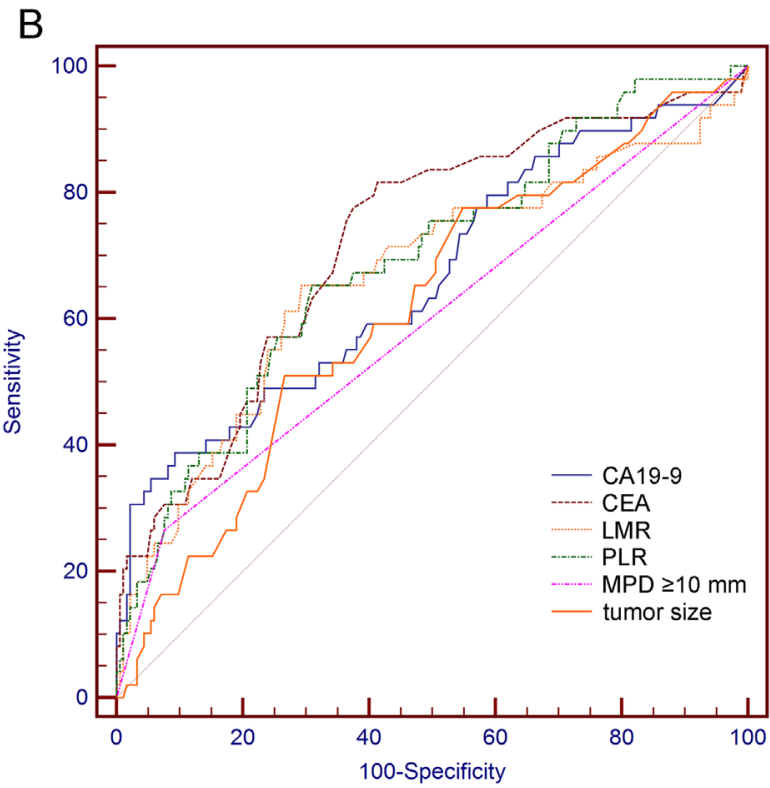

Figure 2: Receiver operating characteristic curves of (A) the predictive index score and (B) the independent predictors in detecting invasive carcinomas. AUC, area under the curve; MPD, main pancreatic duct; CA19-9, carbohydrate antigen 19-9; CEA, carcinoembryonic antigen; PLR, platelet-to-lymphocyte ratio; and LMR, lymphocyte-to-monocyte ratio. 
Table 4: ROC curves comparison analyses of predictive index score and independent predictors $(n=234)$

\begin{tabular}{lccccc}
\hline $\begin{array}{l}\text { ROC curves (predictive } \\
\text { index score vs.) }\end{array}$ & DAUC & SE & $\mathbf{9 5 \%}$ CI & Z statistic & $P$ value \\
\hline CA19-9 & 0.194 & 0.050 & $0.096-0.292$ & 3.870 & $<0.001$ \\
CEA & 0.136 & 0.041 & $0.056-0.216$ & 3.322 & $<0.001$ \\
LMR & 0.191 & 0.044 & $0.057-0.277$ & 4.333 & $<0.001$ \\
PLR & 0.167 & 0.040 & $0.089-0.335$ & 5.035 & $<0.001$ \\
MPD $\geq 10 \mathrm{~mm}$ & 0.263 & 0.035 & $0.195-0.332$ & 7.517 & $<0.001$ \\
Tumor size & 0.241 & 0.048 & $0.090-0.245$ & 4.201 & $<0.001$ \\
\hline
\end{tabular}

ROC, receiver operating characteristic; AUC, area under the curve; SE, standard error; CI, confidence interval; MPD, main pancreatic duct; CA19-9, carbohydrate antigen 19-9; CEA, carcinoembryonic antigen; PLR, platelet-to-lymphocyte ratio; LMR, lymphocyte-to-monocyte ratio.

There are several limitations that are necessary to mention. As a retrospective cohort of resected patients, the true predictive value of these inflammatory factors could not be evaluated mainly due to the lack of followup cases. Furthermore, peripheral blood cells can be affected by various factors, and the detecting utility of the inflammatory markers is limited, particularly in patients with infectious diseases or undergoing invasive tests. In addition, no correlation between the biomarkers and highgrade dysplasia was discovered in our study. The search for novel diagnostic strategies for mucinous PCNs with high-grade dysplasia is urgent, since patients at this phase of PCN can greatly benefit from surgical therapies.

\section{MATERIALS AND METHODS}

Data of 276 patients who underwent surgical resections for mucinous pancreatic cystic neoplasms in Zhong Shan Hospital, Fudan University, from February 2008 to April 2017 were retrospectively evaluated. Patients whose records for preoperative blood cell counts were unavailable, had a history of malignancy or hematological diseases, exhibited infectious diseases or received invasive procedures within two weeks before the operations were excluded (Supplementary Figure 1).

Demographic, clinical and pathological data were collected from the medical records of the selected patients. Routine laboratory tests for albumin, CA19-9, CEA, platelet count, white blood cell count, neutrophil count, lymphocyte count, and monocyte count were performed prior to surgery with a median time of 4 days (IQR 2-5). The NLR and PLR were defined as the ratio of the absolute neutrophil count and platelet count divided by the absolute count of lymphocyte, respectively. Similarly, LMR was calculated as the absolute lymphocyte count divided by the absolute monocyte count. The diameters of the cystic tumor and main pancreatic duct were measured according to the images of the CT or MRI. The largest lesion was evaluated if multifocal tumors existed. All the cases were confirmed by the final pathology of the resected specimens. The tumor differentiation was classified based on the most aggressive histological changes, including low-grade dysplasia, moderate-grade dysplasia, highgrade dysplasia and invasive carcinomas.

This research was approved by the Ethics Committee of Zhong Shan Hospital, and written informed consent was obtained from all the patients.

\section{Statistical analysis}

Continuous variables presented with a median and interquartile range, while categorical variables were described as a whole number and percentage. The distributions of continuous variables among multiple independent groups were compared by the Kruskal-Wallis test. Univariate analyses of categorical variables between two independent groups were performed using the chisquare test. Multivariate analyses were conducted to assess the independent predictors of invasive carcinomas by the logistic regression model with the forward elimination method (likelihood-ratio test). All the above statistical analyses were performed on SPSS version 19.0 software (IBM Corp., Armonk, NY, USA). Receiver operating characteristic (ROC) curves were calculated to determine the optimal cut-off values of the continuous variables. The area under the curve (AUC) of the ROC curves was compared using the method of DeLong et al. [31] with MedCalc version 11.4.2.0 software (MedCalc Software bvba, Ostend, Belgium). A two-sided $P$ value of less than 0.05 was defined as significant.

\section{CONCLUSION}

The systemic inflammation response is closely related to the progression of mucinous pancreatic cysts. Circulating cell-based biomarkers PLR and LMR have been demonstrated as the independent predictors of mucinous PCN patients harboring invasive carcinomas. 
Our predictive model is reliable in identifying invasive malignancies and can be used as a convenient tool for the preoperative assessments of pancreatic cystic neoplasms, and all the indexes are easily extracted from routine tests. However, the exact mechanisms regarding the interaction between inflammation and mucinous PCN are still unknown, and anti-inflammatory therapies may slow down the disease course or even prevent malignant changes in pancreatic cysts, which need to be clarified in the future.

\section{Abbreviations}

PCN, pancreatic cystic neoplasm; NLR, neutrophilto-lymphocyte ratio; PLR, platelet-to-lymphocyte ratio; LMR, lymphocyte-to-monocyte ratio; ROC, receiver operating characteristic; AUC, area under the curve; IPMN, intraductal papillary mucinous neoplasm; $\mathrm{MCN}$, mucinous cystic neoplasm; IQR, interquartile range; MPD, main pancreatic duct; CA19-9, carbohydrate antigen 19-9; CEA, carcinoembryonic antigen; BD-IPMN, branch-duct IPMN; MRI, magnetic resonance imaging; CT, computed tomography.

\section{Author contributions}

The study was designed by Wenhui Lou and Dansong Wang. It was analyzed and written by Wentao Zhou and Yefei Rong. Tiantao Kuang and Yadong Xu collected the data and conducted the statistical analyses. Xiaojing Shen and Yuan Ji checked the pathological diagnosis of each case in this study. In addition, all the authors reviewed and approved the final version of the manuscript.

\section{CONFLICTS OF INTEREST}

All the authors declare that they have no conflicts of interest.

\section{FUNDING}

This study was supported by grants from the National Natural Science Foundation of China (No. 81401923).

\section{REFERENCES}

1. Moris D, Damaskos C, Spartalis E, Papalampros A, Vernadakis S, Dimitroulis D, Griniatsos J, Felekouras E, Nikiteas N. Updates and critical evaluation on novel biomarkers for the malignant progression of intraductal papillary mucinous neoplasms of the pancreas. Anticancer Res. 2017; 37:2185-94.

2. Tanaka M, Chari S, Adsay V, Fernandez-del Castillo C, Falconi M, Shimizu M, Yamaguchi K, Yamao K, Matsuno
S. International consensus guidelines for management of intraductal papillary mucinous neoplasms and mucinous cystic neoplasms of the pancreas. Pancreatology. 2006; 6:17-32.

3. Tanaka M, Fernandez-del Castillo C, Adsay V, Chari S, Falconi M, Jang JY, Kimura W, Levy P, Pitman MB, Schmidt CM, Shimizu M, Wolfgang CL, Yamaguchi $\mathrm{K}$, et al. International consensus guidelines 2012 for the management of IPMN and MCN of the pancreas. Pancreatology. 2012; 12:183-97.

4. Hoffman RL, Gates JL, Kochman ML, Ginsberg GG, Ahmad NA, Chandrasekhara V, Furth EE, Vollmer CM, Drebin JA. Analysis of cyst size and tumor markers in the management of pancreatic cysts: support for the original Sendai criteria. J Am Coll Surg. 2015; 220:1087-95.

5. Abbott DE, Ahmad SA. Comparison of the sendai and fukuoka consensus guidelines for the management of mucinous cystic lesions of the pancreas: are we making progress? Ann Surg Oncol. 2014; 21:1770-2.

6. Goh BK, Tan DM, Ho MM, Lim TK, Chung AY, Ooi LL. Utility of the sendai consensus guidelines for branch-duct intraductal papillary mucinous neoplasms: a systematic review. J Gastrointest Surg. 2014; 18:1350-7.

7. Goh BK, Lin Z, Tan DM, Thng CH, Khor CJ, Lim TK, Ooi LL, Chung AY. Evaluation of the fukuoka consensus guidelines for intraductal papillary mucinous neoplasms of the pancreas: results from a systematic review of 1,382 surgically resected patients. Surgery. 2015; 158:1192-202.

8. Balkwill F, Mantovani A. Inflammation and cancer: back to Virchow? Lancet. 2001; 357:539-45.

9. Bausch D, Pausch T, Krauss T, Hopt UT, Fernandez-delCastillo C, Warshaw AL, Thayer SP, Keck T. Neutrophil granulocyte derived MMP-9 is a VEGF independent functional component of the angiogenic switch in pancreatic ductal adenocarcinoma. Angiogenesis. 2011; 14:235-43.

10. Gong L, Cumpian AM, Caetano MS, Ochoa CE, De la Garza MM, Lapid DJ, Mirabolfathinejad SG, Dickey BF, Zhou Q, Moghaddam SJ. Promoting effect of neutrophils on lung tumorigenesis is mediated by CXCR2 and neutrophil elastase. Mol Cancer. 2013; 12:154.

11. Coussens LM, Werb Z. Inflammation and cancer. Nature. 2002; 420:860-7.

12. Mantovani A, Allavena P, Sica A, Balkwill F. Cancer-related inflammation. Nature. 2008; 454:436-44.

13. Mano Y, Shirabe K, Yamashita Y, Harimoto N, Tsujita E, Takeishi K, Aishima S, Ikegami T, Yoshizumi T, Yamanaka T, Maehara Y. Preoperative neutrophil-to-lymphocyte ratio is a predictor of survival after hepatectomy for hepatocellular carcinoma: a retrospective analysis. Ann Surg. 2013; 258:301-5.

14. Sugiura T, Uesaka K, Kanemoto H, Mizuno T, Okamura Y. Elevated preoperative neutrophil-to-lymphocyte ratio as a predictor of survival after gastroenterostomy in patients with advanced pancreatic adenocarcinoma. Ann Surg Oncol. 2013; 20:4330-7. 
15. Raungkaewmanee S, Tangjitgamol S, Manusirivithaya S, Srijaipracharoen S, Thavaramara T. Platelet to lymphocyte ratio as a prognostic factor for epithelial ovarian cancer. $\mathrm{J}$ Gynecol Oncol. 2012; 23:265-73.

16. Asari S, Matsumoto I, Toyama H, Shinzeki M, Goto T, Ishida J, Ajiki T, Fukumoto T, Ku Y. Preoperative independent prognostic factors in patients with borderline resectable pancreatic ductal adenocarcinoma following curative resection: the neutrophil-lymphocyte and plateletlymphocyte ratios. Surg Today. 2016; 46:583-92.

17. Gemenetzis G, Bagante F, Griffin JF, Rezaee N, Javed AA, Manos LL, Lennon AM, Wood LD, Hruban RH, Zheng L, Zaheer A, Fishman EK, Ahuja N, et al. Neutrophilto-lymphocyte ratio is a predictive marker for invasive malignancy in intraductal papillary mucinous neoplasms of the pancreas. Ann Surg. 2017; 266:339-45.

18. Kaimakliotis P, Riff B, Pourmand K, Chandrasekhara V, Furth EE, Siegelman ES, Drebin J, Vollmer CM, Kochman ML, Ginsberg GG, Ahmad NA. Sendai and fukuoka consensus guidelines identify advanced neoplasia in patients with suspected mucinous cystic neoplasms of the pancreas. Clin Gastroenterol Hepatol. 2015; 13:1808-15.

19. Sighinolfi M, Quan SY, Lee Y, Ibaseta A, Pham K, Dua MM, Poultsides GA, Visser BC, Norton JA, Park WG. Fukuoka and AGA criteria have superior diagnostic accuracy for advanced cystic neoplasms than sendai criteria. Dig Dis Sci. 2017; 62:626-32.

20. Watanabe $Y$, Nishihara K, Niina Y, Abe Y, Amaike T, Kibe S, Poultsides GA, Visser BC, Norton JA, Park WG. Validity of the management strategy for intraductal papillary mucinous neoplasm advocated by the international consensus guidelines 2012: a retrospective review. Surg Today. 2016; 46:1045-52.

21. Ma GK, Goldberg DS, Thiruvengadam N, Chandrasekhara V, Kochman ML, Ginsberg GG, Vollmer CM, Ahmad NA. Comparing American Gastroenterological Association pancreatic cyst management guidelines with fukuoka consensus guidelines as predictors of advanced neoplasia in patients with suspected pancreatic cystic neoplasms. J Am Coll Surg. 2016; 223:729-37.

22. Goh BK, Tan DM, Chan CY, Lee SY, Lee VT, Thng CH, Low AS, Tai DW, Cheow PC, Chow PK, Ooi LL, Chung AY. Are preoperative blood neutrophil-to-lymphocyte and platelet-to-lymphocyte ratios useful in predicting malignancy in surgically-treated mucin-producing pancreatic cystic neoplasms? J Surg Oncol. 2015; 112:366-71.

23. Arima K, Okabe H, Hashimoto D, Chikamoto A, Kuroki H, Taki K, Kaida T, Higashi T, Nitta H, Komohara Y, Beppu T, Takeya M, Baba H. The neutrophil-to-lymphocyte ratio predicts malignant potential in intraductal papillary mucinous neoplasms. J Gastrointest Surg. 2015; 19:2171-7.

24. Goh BK, Tan YM, Cheow PC, Chung YF, Chow PK, Wong WK, Ooi LL. Cystic neoplasms of the pancreas with mucinproduction. Eur J Surg Oncol. 2005; 31:282-7.

25. Klinger $\mathrm{MH}$, Jelkmann W. Role of blood platelets in infection and inflammation. J Interferon Cytokine Res. 2002; 22:913-22.

26. Dabrow MB, Francesco MR, McBrearty FX, Caradonna S. The effects of platelet-derived growth factor and receptor on normal and neoplastic human ovarian surface epithelium. Gynecol Oncol. 1998; 71:29-37.

27. Stone RL, Nick AM, McNeish IA, Balkwill F, Han HD, Bottsford-Miller J, Rupairmoole R, Armaiz-Pena GN, Pecot CV, Coward J, Deavers MT, Vasquez HG, Urbauer D. Paraneoplastic thrombocytosis in ovarian cancer. N Engl J Med. 2012; 366:610-8.

28. Salazar-Onfray F, Lopez MN, Mendoza-Naranjo A. Paradoxical effects of cytokines in tumor immune surveillance and tumor immune escape. Cytokine Growth Factor Rev. 2007; 18:171-82.

29. Bellone G, Turletti A, Artusio E, Mareschi K, Carbone A, Tibaudi D, Robecchi A, Emanuelli G, Rodeck U. Tumor-associated transforming growth factor-beta and interleukin-10 contribute to a systemic Th2 immune phenotype in pancreatic carcinoma patients. Am J Pathol. 1999; 155:537-47.

30. Lee HW, Choi HJ, Ha SJ, Lee KT, Kwon YG. Recruitment of monocytes/macrophages in different tumor microenvironments. Biochim Biophys Acta. 2013; 1835:170-9.

31. DeLong ER, DeLong DM, Clarke-Pearson DL. Comparing the areas under two or more correlated receiver operating characteristic curves: a nonparametric approach. Biometrics. 1988; 44:837-45. 